\title{
Thrombotic thrombocytopenic purpura associated with the acquired immune deficiency syndrome
}

\author{
ANAND Kumar, MD, JeAN WANG, MD, DAVID SUTtON, MD, ERIC J BOW, MD
}

\begin{abstract}
A Kumar, J WANG, D Sutton, EJ Bow. Thrombotic thrombocytopenic purpura associated with the acquired immune deficiency syndrome. Can $J$ Infect Dis 1992;3(1):37-41. A bisexual male presented with acute thrombotic thrombocytopenic purpura (TTP) in association with established acquired immune deficiency syndrome. The patient had classic clinical and laboratory findings of TTP and responded well to plasmapheresis therapy. Previously reported cases of TTP in association with human immunodeficiency virus (HIV) infection are briefly reviewed. Basic concepts in the pathogenesis of TTP are examined in reference to HIV infection.
\end{abstract}

Key Words: Acquired immune deficiency syndrome. Anemia. Human immunodeficiency virus. Thrombocytopenia, Thrombotic microangiopathy. Thrombotic thrombocytopenic purpura

\section{Purpura thrombocytopénique thrombotique associé au syndrome d'immunodéficience acquise}

RESUME: Un patient bisexuel s'est présenté avec un purpura thrombocytopénique thrombotique aigu (PTT) associé à un syndrome d'immunodéficience acquise diagnostiqué. Les résultats cliniques et trouvailles de laboratoire étaient classiques et le patient a réagi favorablement à une plasmaphérèse. D’autres cas de PTT associé au syndrome d'immunodéficience acquise sont rapidement évoqués. Les notions fondamentales de la pathogenèse du PTT sont examinées par rapport à l'infection à VIH (virus de l'immunodéficience acquise).

$\mathrm{T}$ HROMBOTIC THROMBOCYTOPENIC PURPURA (TTP), FIRST described by Moscowitz in 1924 (1), is characterized by the pentad of microangiopathic hemolytic anemia, consumptive thrombocytopenia, fluctuating neurological deficits, renal failure and fever. Recently. several cases of TTP associated with human im- munodeficiency virus (HIV) infection have been reported (2-11). The authors report a case of TTP in association with an established diagnosis of acquired immune deficiency syndrome (AIDS), and briefly review reported cases of TTP associated with HIV infection to date.

Section of Critical Care, Department of Medicine, Rush-Presbyterian-St Luke's Medical Center, Chicago, Illinois, USA; Department of Hematology-Oncology. Toronto Western Hospital. Toronto. Ontario; and Sections of Hematology-Oncology and Infectious Diseases, St Boniface Hospital, Winnipeg, Manitoba

Correspondence and reprints: Dr Anand Kumar. Critical Care Fellow, Section of Critical Care, Department of Medicine. Rush-Presbyterian-St Lukes Medical Center, 1653 West Congress Parkway. Chicago, IL 60612, USA

Received for publication April 24, 1990. Accepted November 7. 1990 


\section{CASE PRESENTATION}

The patient was a 44-year-old HIV seropositive bisexual male whose defining incident for AIDs was an episode of Pneumocystis carinii pneumonia eight months prior to the presenting illness. Three days prior to admission, the patient developed diarrhea and vomiting. He subsequently presented to the emergency department of a community hospital with expressive aphasia. Medications on admission included oral acyclovir $200 \mathrm{mg}$ six times daily, oral zidovudine (AZT) $200 \mathrm{mg}$ three times daily, and aerosolized pentamidine by nebulizer $60 \mathrm{mg}$ every two weeks. Two weeks prior to admission, hemoglobin was $110 \mathrm{~g} / \mathrm{L}$, platelet count $157 \times 10^{9} / \mathrm{L}$ and leukocyte count $3.0 \times 10^{9} / \mathrm{L}$, with an absolute T4 helper lymphocyte count of $0.08 \times 10^{9} / \mathrm{L}$ and a $\mathrm{T} 4 / \mathrm{T} 8$ ratio of 0.23 .

On assessment in the emergency department, the patient had an oral temperature of $38.7^{\circ} \mathrm{C}$. There were bilateral preretinal hemorrhages, and petechiae were apparent on the hard and soft palate. Apart from expressive aphasia, no other focal neurological deficits were present. Admission laboratory values included a hemoglobin of $61 \mathrm{~g} / \mathrm{L}$, platelet count $11 \times 10^{9} / \mathrm{L}$ and leukocyte count $5.8 \times 10^{9} / \mathrm{L}$. Examination of a peripheral blood film revealed many schistocytes, marked polychromasia and few platelets. Prothrombin time was $11 \mathrm{~s}$ with a control value of $12 \mathrm{~s}$. Partial thromboplastin time was $31 \mathrm{~s}$ with a control value of $30 \mathrm{~s}$.

Blood urea nitrogen and creatinine were significantly elevated at $14 \mathrm{mmol} / \mathrm{L}$ and $200 \mu \mathrm{mol} / \mathrm{L}$, respectively. Urinalysis demonstrated hyaline granular casts.

The patient was given six units of platelets, three units of packed red blood cells, and two units of fresh frozen plasma.

Within $12 \mathrm{~h}$ of blood product infusion, three generalized seizures occurred. Subsequently, a persistent coma developed. The patient was then transferred to a tertiary care facility.

The patient was unresponsive to noxious stimuli, but pupillary, oculocephalic, corneal and gag reflexes were present. Focal neurological abnormalities were not noted. Otherwise, physical findings were unchanged from the initial assessment. Temperature was $38.6^{\circ} \mathrm{C}$ orally. Hemoglobin was $68 \mathrm{~g} / \mathrm{L}$, platelet count $16 \times 10^{9} / \mathrm{L}$, and leukocyte count $4.8 \times 10^{9} / \mathrm{L}$. Additional laboratory data included lactate dehydrogenase 556 $\mathrm{U} / \mathrm{L}$, total bilirubin $44 \mu \mathrm{mol} / \mathrm{L}$, and serum haptoglobin $0.106 \mathrm{~g} / \mathrm{L}$. Coagulation studies were normal. Hepatitis B surface and e antigens were present in serum. A computed tomography scan of the head with contrast was normal. Gingival biopsy was nondiagnostic.

Daily plasma exchanges were begun and continued for 13 days. Four to $5 \mathrm{~L}$ of plasma were exchanged with fresh frozen plasma daily for the first three days, followed by 3 to $3.5 \mathrm{~L}$ exchanges daily to completion. The patient received dipyridamole $400 \mathrm{mg}$ daily and acetylsalicylic acid $325 \mathrm{mg}$ daily, first by nasogastric tube and then orally for a total of 14 days. Glucocorticoids were not given. Intravenous cefoxitin was given for a right lung infiltrate suspected to be secondary to aspiration.

After the second plasma exchange, the patient awoke but remained confused. Neurological status returned to normal by the fifth day of treatment. The platelet count started to rise after the third day of therapy. Lactate dehydrogenase and bilirubin levels returned to normal. Renal function recovered completely by 10 days of therapy. After 15 days, the patient was discharged with a hemoglobin of $100 \mathrm{~g} / \mathrm{L}$ and a platelet count of $108 \times 10^{9} / \mathrm{L}$.

\section{DISCUSSION}

Individuals with HIV infection exhibit a number of abnormalities and diseases of the hematological system. These include idiopoathic thrombocytopenic purpura, lymphopenia, neutropenia, Coombs positive hemolytic anemia, polyclonal hypergammaglobulinemia and high grade lymphomas. Further, bone marrow involvement by secondary infectious processes such as Mycobacterium avium-intracellulare may cause anemia. In addition, pharmacological therapy of HIV infection and its secondary infectious complications often results in hematological toxicity. AZT therapy is often dose-limited by anemia and leukopenia. Pentamidine is associated with thrombocytopenia.

Other drugs commonly used for secondary infectious complications of HIV infection (ganciclovir, pyrimethamine, trimethoprim-sulphamethoxazole and foscarnet) also occasionally result in hematological toxicity, particularly thrombocytopenia.

Moschowitz (1) is credited with the first description of the disease now called 'thrombotic thrombocytopenic purpura', but not until 1953, when Monroe and Strauss (12) suggested a microangiopathic process, was the nature of the anemia understood. The hallmarks of this disease are microangiopathic hemolytic anemia, consumptive thrombocytopenia and fluctuating neurological abnormalities. Fever and renal dysfunction were added to the classic triad of TTP by Lukes et al in 1961 (13).

TTP has only recently been reported in association with HIV infection. Jokela et al (2) first reported the association in 1987. Since then, there have been 24 cases described including the present case (3-11). One report (an abstract of six cases [11]), contained limited information and is therefore analyzed only with respect to epidemiological data. Two cases are excluded from review because of insufficient documented evidence of HIV infection $(4,9)$. Of 22 reported cases, 18 occurred in men. Ten of the 13 in whom sexual orientation was mentioned were homosexuals. Intravenous drug use was noted in seven cases including two women. A third woman was the sexual partner of an intravenous drug user. Twelve were documented to be HIV seropositive at 
or within weeks after diagnosis of TTP. Nine others were felt to have probable HIV infection based on a combination of persistent generalized lymphadenopathy, secondary infections, secondary malignancies or abnormal T4/T8 lymphocyte ratio and a history of high risk behaviour. One was not diagnosed as being HIV seropositive until one year after presentation with TTP. In total, 10 of 22 cases fit into group II of the Center for Disease Control classification of HIV infection (14) at presentation with TTP. Four others belonged to group III. Group IV was represented by eight patients: five in subgroup $\mathrm{C} 1$, three in subgroup $\mathrm{C} 2$ and two in subgroup D. Both subgroup D patients were also represented in subgroup C1. Five of the eight group IV cases originated from a single report of six cases from France (11).

The presentation of TTP in these patients is similar to that of HIV-unrelated TTP cases. The most characteristic finding is microangiopathic hemolytic anemia characterized by red blood cell fragments on the peripheral smear. Schistocytes were seen in all 16 cases including the present case. Hemoglobin was typically less than $90 \mathrm{~g} / \mathrm{L}$ except in one case, where it was 106 $\mathrm{g} / \mathrm{L}$. Hematocrit (when noted) was less than 0.26 in all cases. Platelet count averaged $19 \times 10^{9} / \mathrm{L}$. A temperature of greater than $38^{\circ} \mathrm{C}$ was present in 11 of 14 cases in which temperature was noted. Neurological symptoms were present in 13 of 16 cases and varied from confusion to coma. Deficits such as seizures, aphasia and hemiplegia occurred in five cases including the present. Renal dysfunction resulted in a creatinine level of greater than $120 \mu \mathrm{mol} / \mathrm{L}$ in 10 of 15 cases.

The classic triad of neurological symptoms, consumptive thrombocytopenia and microangiopathic hemolytic anemia occurred in 13 of 16 patients (including the present), but the full pentad was present in only four. Typical hyaline thrombi composed of fibrin and platelets in the small arterioles were noted on either biopsy (lymph node, gingiva or bone marrow) or post mortem pathology in seven of 10 cases in which tissue was available.

Thirteen of 16 reported cases survived on standard treatment with plasmapheresis $(2-5,8)$ or plasma infusion $(6,7,9)$ and glucocorticoids $(2-5,7,9,10)$, acetylsalicylic acid $(2-7,9)$, dipyridamole $(2-7,9)$, high dose gamma globulin (7), vincristine $(3,6)$, or no additional treatment $(3,4,8)$. This is consistent with $81 \%$ survival described in combined series of plasmapheresis therapy (15). All three deaths occurred in the first $24 \mathrm{~h}$ after presentation and before initiation of plasmapheresis. Of note in the present patient is the typically early neurological response after initiation of plasma therapy. In addition, the present patient had a sudden and dramatic deterioration after platelet infusion, as has been described in the past. A recent review suggests that platelet transfusions are specifically contraindicated in TTP (16).
The pathogenesis of TTP is not yet clearly delineated. Both the presence of a platelet aggregating factor and the absence of an aggregation inhibitor have been suggested. Lian et al (17) have described a platelet aggregating factor in the plasma of $50 \%$ of cases of TTP and a time-dependent inhibition of its platelet aggregating ability by coincubation with normal plasma. Unusually large multimers of von Willebrand factor, which are able to cause platelet aggregation, have been isolated in cases of TTP $(18,19)$. Moake $(20)$ has suggested that these multimers develop due to a deficiency or reduced activity of a specific protease.

Prostacyclin deficiency is another potential cause of the platelet aggregation seen in TTP (21). Other theories of pathogenesis involve antiplatelet antibodies, circulating immune complexes and antiendothelial antibodies (22-26).

Regardless of the pathogenesis of TTP, the immunological perturbations of HIV infection probably underlie the association of the two diseases. HIV infection is known to be associated with a large number of immunological abnormalities apart from an abnormal T4/T8 lymphocyte ratio.

A number of autoimmune phenomena have been associated with HIV infection. These include antinuclear, antilymphocyte, antigranulocyte, anticardiolipin, antiplatelet and Coombs antibodies, as well as rheumatoid factor and lupus anticoagulant $(27,28)$. Platelet-associated antibodies have been specifically implicated in the pathogenesis of TTP $(22,29)$ and have been isolated in at least one case of TTP associated with HIV infection (3). In addition, it has been suggested that the genesis of Lian's platelet aggregating factor may involve defects in the humoral immune system (30). Further, Moake (20) has noted that processing of the unusually large von Willebrand factor multimers may be deficient due to autoantibodies in some cases of TTP.

In addition, circulating immune complexes are frequently seen in both HIV infection and TTP $(23,31)$. These complexes may promote the formation of microthrombi such that endothelial cell damage leads to prostacyclin deficiency followed by platelet adhesion and aggregation $(21,32)$.

Finally, cytokines such as tumour necrosis factor (TNF)/ cachexin and interleukin-1 (IL-1) are elevated in some HIV-infected individuals $(33,34)$. These cytokines have significant procoagulant effects on endothelial cell function, including decreased fibrinolytic activity and decreased activity of protein $\mathrm{C}$ and protein $\mathrm{S}$ pathways (35). In addition, TNF and IL-1 both increase the production of another substance, platelet activating factor $(36,37)$. This substance has powerful platelet aggregating properties and is know to cause thrombocytopenia in animal models $(38,39)$.

Despite these potential mechanisms of an association, it remains undetermined whether an increased frequency of TTP in HIV-infected individuals exists. The 
fact that cases of TTP in association with HIV infection have been reported in the literature so late after the initial description of AIDS suggests at least three possibilities. Clinical expression of the disease in HIV-infected individuals may require a longer period of subclinical development than other, more frequent HIV complications. Alternately, the association may be so rare that it is not noted until sufficient numbers of HIV-infected individuals develop (4). Finally, previous TTP manifestations in HIV-infected individuals may have been erroneously ascribed to other causes.

The clinical presentation of TTP in HIV-infected adults is similar to that seen in the absence of HIV infection. The diagnosis of TTP in HIV-infected individuals may, however, be particularly difficult be-

ACKNOWLEDGEMENTS: The authors gratefully acknowledge the assistance of Armando Susmano, MD, Aparna Kumar, MD, and Darlene Rivera in translation of non-English literature.

\section{REFERENCES}

1. Moschowitz $\mathrm{E}$. Hyaline thrombosis of the terminal arterioles and capillaries - A hitherto undescribed disease. Proc NY Pathol Soc 1924;24:21-4.

2. Jokela J, Flynn T, Henry K. Thrombotic thrombocytopenic purpura in a human immunodeficiency virus (HIV)-seropositive homosexual man. Am J Hematol 1987;25:341-3.

3. Meisenberg BR, Robinson WL, Mosley CA, Duke MS, Rabetoy GM, Kosty MP. Thrombotic thrombocytopenic purpura in human immunodeficiency virus (HIV)-seropositive males. Am J Hematol 1988;27:2 12-5.

4. Leaf AN, Laubenstein LJ, Raphael B, Hochster H, Baez L, Karpatkin S. Thrombotic thrombocytopenic purpura with human immunodeficiency virus type 1 (HIV-1) infection. Ann Intern Med 1988;109:194-7.

5. Nair JMG, Bellevue R, Bertoni M, Dosik H. Thrombotic thrombocytopenic purpura in patients with the acquired immunodeficiency syndrome (AIDS)-related complex. A report of two cases. Ann Intern Med 1988;109:209-12.

6. Botti AC, Hyde P, DiPillo F. Thrombotic thrombocytopenic purpura in a patient who subsequently developed the acquired immunodeficiency syndrome (AIDS). Ann Intern Med 1988; 109;242-3.

7. DeNorbriga J, Chu-Fong A, Elizalde A. Thrombotic thrombocytopenic purpura (TTP) in a human immunodeficiency virus (HIV)-positive patient Successful treatment with high dose gamma globulin. Proc Annu Meet Am Soc Clin Oncol 1989;86:6. (Abst)

8. Besalduch J, Altes J, Morey M, Villalonga C. Thrombotic thrombocytopenic purpura and infection by the human immunodeficiency virus. Med Clin (Barc) 1989;92:195-6. (Lett)

9. Platanias LC, Paiusco D, Bernstein S, Murali MR. Thrombotic thrombocytopenic purpura as the first manifestation of human immunodeficiency virus infection. Am J Med 1989;87;699-700. (Lett)

10. Bell MD, Barnhart JS, Martin JM. Thrombotic thrombocytopenic purpura causing sudden unexpected death - A series of eight patients.

J Forensic Sci 1990;35:601-13.

11. Khuong M, De Truchis P, Oksenhendler E, Matheron S, Dosquet P, Clauvel JP. Thrombotic microangiopathy and cause individually, fever, thrombocytopenia, anemia, neurological deficits and renal failure can all be caused by HIV infection, various secondary complications and treatment.

Despite these difficulties, thrombocytopenia and anemia in combination with fever, neurological deficits or renal dysfunction in HIV-infected individuals should trigger consideration of TTP. In addition, although the clinical association has been infrequently documented, any patient with evidence of TTP should undergo an HIV antibody test. Plasmapheresis, which is clearly effective in HIV-associated TTP, is the preferred treatment, but appropriate early therapy can only be delivered by prompt recognition of the clinical syndrome.

HIV infection. International Conference on AIDS. 1989;5:263. (Abst)

12. Monroe WM, Strauss HA. Intravascular hemolysis - A morphologic study of schizocytes in thrombotic purpura and other diseases. South Med J 1953;46:837-42.

13. Lukes RJ, Rath CE, Steussy CN, Mailliard J. Thrombotic thrombocytopenic purpura - Clinical and pathologic findings in 49 cases. Blood 1961;17:366. (Abst)

14. Centers for Disease Control. Classification system for human T-lymphotropic virus type

III/lymphadenopathy-associated virus infections. MMWR 1986:35:334-9.

15. Shepard KV, Bukowski RM. The treatment of thrombotic thrombocytopenic purpura with exchange transfusions, plasma infusions and plasma exchange. Semin Hematol 1987;24:178-93.

16. Gordon LI, Kwaan HC, Rossi EC. Deleterious effects of platelet transfusions and recovery thrombocytosis in patients with thrombotic microangiopathy. Semin Hematol 1987;24:194-201.

17. Lian EC, Harkness DR, Byrnes JJ, Wallach H, Nunez R. Presence of a platelet aggregating factor in the plasma of patients with thrombotic thrombocytopenic purpura (TTP) and its inhibition by normal plasma. Blood 1979:53:333-8.

18. Moake JL, Turner NA, Stathopoulos NA, Nolasco LH, Hellums JD. Shear-induced platelet aggregation can be mediated by vWF released from platelets, as well as by exogenous large or unusually large vWF multimers, requires adenosine diphosphate, and is resistant to aspirin. Blood 1988;71:1366-74.

19. Moake JL, Turner NA, Stathopoulos NA, Nolasco LH, Hellums JD. Involvement of large plasma von Willebrand factor (vWF) multimers and usually large vWF forms derived from endothelial cells in shear stress-induced platelet aggregation. J Clin Invest 1986;78:1456-61.

20. Moake JL. Von Willebrand factor and the pathophysiology of thrombotic thrombocytopenia: From human studies to a new animal model. Lab Invest 1988:59:415-7.

21. Hensby CN, Lewis PJ, Hilgard P, Mufti GJ, Hows J, Webster J. Prostacyclin deficiency in thrombotic thrombocytopenic purpura. Lancet 1979;ii:748. (Lett)

22. Morrison J, McMillan R. Elevated platelet-associated IgG in thrombotic thrombocytopenic purpura. JAMA 1977;238:1944-5.

23. Meister RJ, Sacker RA, Phillips T. Immune complexes in thrombotic thrombocytopenic purpura. Ann Intern Med 1979;90:717. (Lett)

24. Bayer AS, Theofilopoulos AN, Eisenberg R, Friedman SD, 
Guze LB. Thrombotic thrombocytopenic purpura-like syndrome associated with infective endocarditis. A possible immune complex disorder. JAMA 1977;238:406-10.

25. Wall RT, Harker LA, Quadracci LJ, Striker GE. Immune-mediated endothelial cell injury in the pathogenesis of thrombotic thrombocytopenic purpura (TTP). Clin Res 1977;25:350A.

26. Foster PA, Anderson JC. Effects of plasma from patients with thrombotic thrombocytopenic purpura (TTP) on cultured human endothelial cells. Blood 1979;54:240A.

27. Kaye BR. Rheumatologic manifestations of infection with human immunodeficiency virus (HIV). Ann Intern Med 1989;11:158-67.

28. Kopelman RG, Zolla-Pazner S. Association of human immunodeficiency virus infection and autoimmune phenomena. Am J Med 1988;84:82-8.

29. Sims PJ, Boswell EB. Elevated platelet bound IgG associated with an episode of thrombotic thrombocytopenic purpura. Blood 1981;58:682-4.

30. Aster RH. Plasma therapy for thrombotic thrombocytopenic purpura. Sometimes it works but why? N Engl J Med 1985;312:985-7.

31. McDougal JS, Hubbard M, Nicholson JK, et al. Immune complexes in the acquired immunodeficiency syndrome (AIDS): Relationship to disease manifestation, risk group and immunologic defect. J Clin Immunol 1985;5:130-8.

32. Remuzzi G, Rossi E, Misiani R, et al. Prostacyclin and thrombotic microangiopathy. Semin Thromb Hemost 1980;6:391-4.
33. Lahdevirta J, Maury CPJ, Teppo A, Reppo H. Elevated levels of circulating cachectin/tumor necrosis factor in patients with acquired immmunodeficiency syndrome. Am J Med 1988;85:289-91.

34. Lepe-Zuniga JL, Mansell PWA, Hersh EM. Idiopathic production of interleukin 1 in the acquired immunodeficiency syndrome. J Clin Microbiol 1987;25:1695-700.

35. Stern DM, Kaiser E, Nawroth PP. Regulation of the coagulation system by vascular endothelial cells. Haemostasis 1988;18:202-14.

36. Camussi G, Bussolino F, Salvidio G, Baglioni C. Tumor necrosis factor/cachectin stimulates peritoneal macrophages, polymorphonuclear neutrophils and vascular endothelial cells to synthesize and release platelet-activating factor. J Exp Med 1987; 166:1390-400.

37. Bussolino F, Camussi G, Baglioni C. Synthesis and release of platelet-activating factor by human vascular endothelial cells treated with tumor necrosis factor or interleukin 1. J Biol Chem 1988:263:11856-61

38. Kinlough-Rathbone RL, Packham MA, Reimers HJ, Cazenave JP, Mustard JF. Mechanisms of platelet shape change, aggregation and release induced by collagen, thrombin or A23,187. J Lab Clin Med 1977;90:707-19.

39. Mackie IJ, Bull HA. Normal haemostasis and its regulation. Blood Rev 1989;3:237-50. 


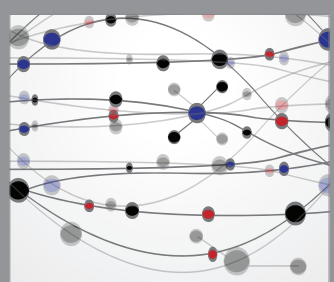

The Scientific World Journal
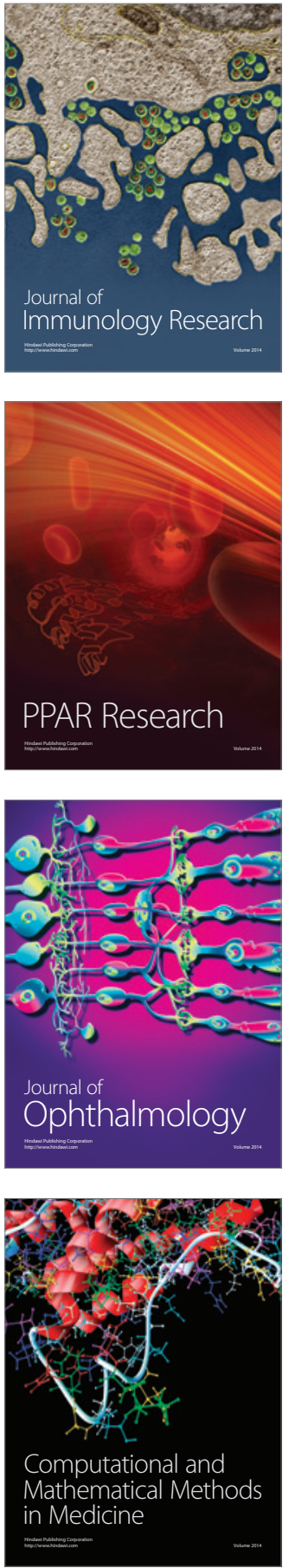

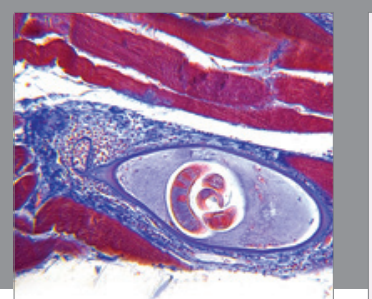

Gastroenterology Research and Practice

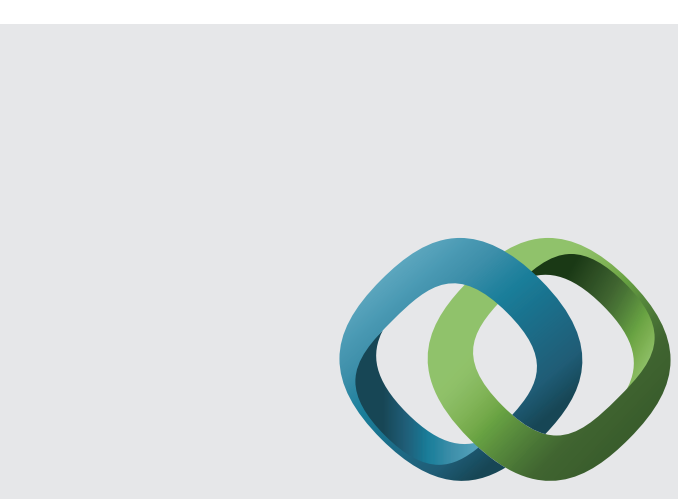

\section{Hindawi}

Submit your manuscripts at

http://www.hindawi.com
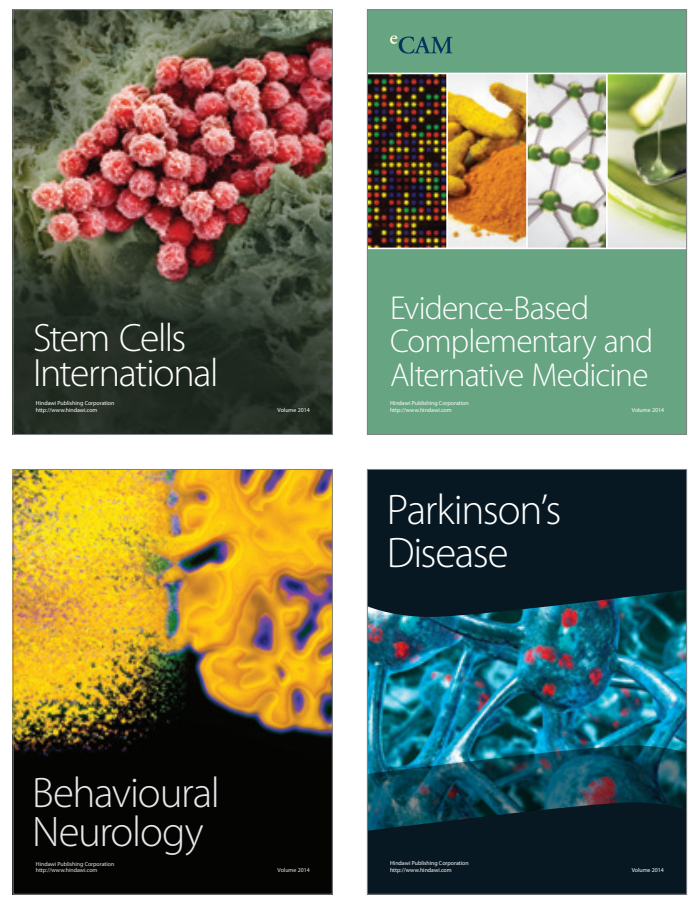
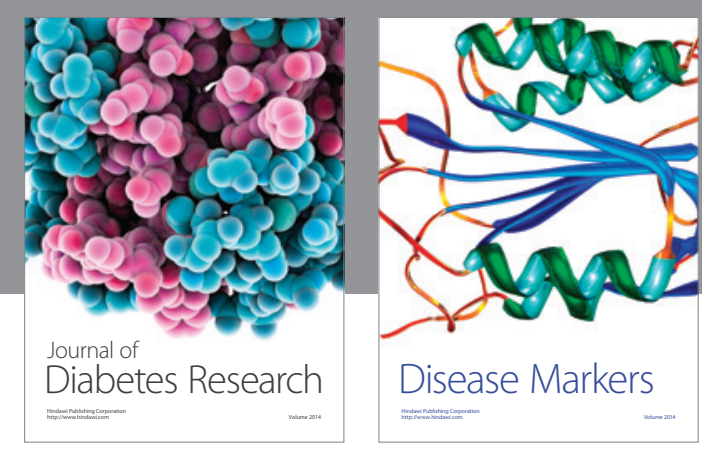

Disease Markers
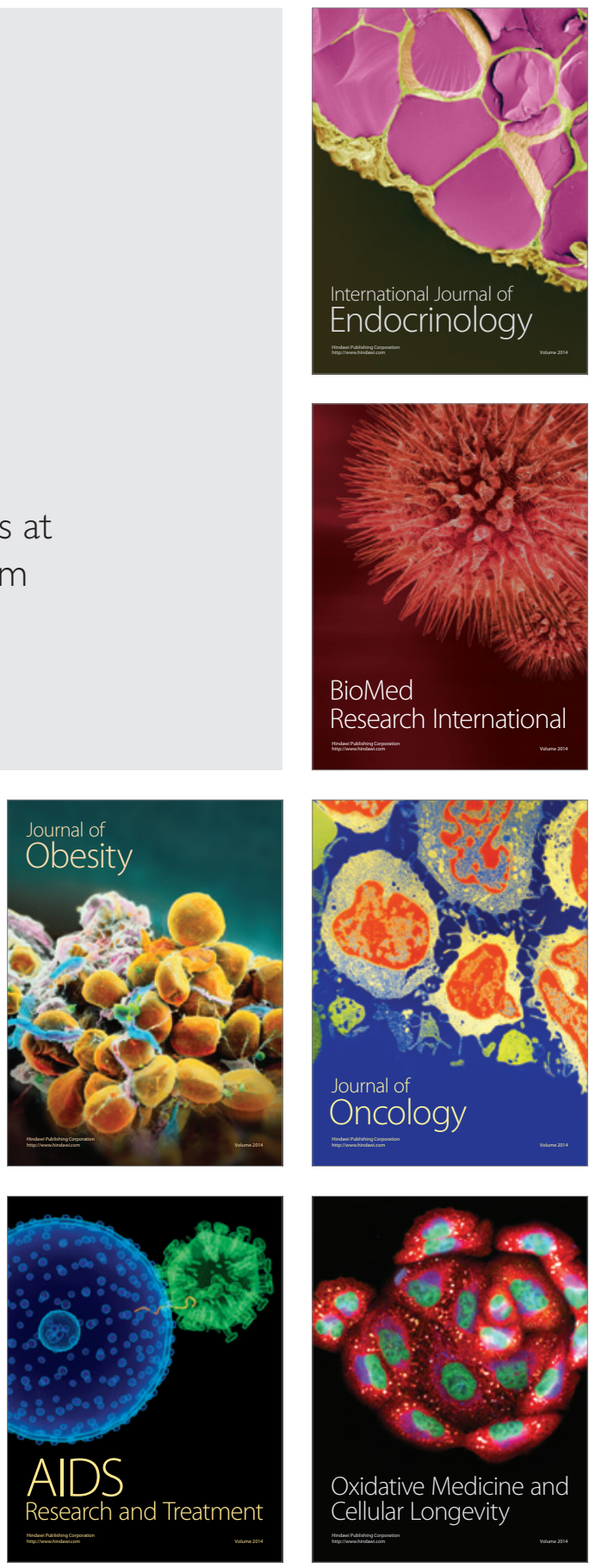